permeate the whole of Chapter 8 on the principles of piezo-electricity. The correct equation (2) is also used as a basis for many of the equations in this same chapter, and the reader is therefore obliged to examine closely the origin of the formulæ he uses. The formulæ affected are the basically important linear equations which give the elastic stresses and electric field intensities as functions of the elastic strains and electric displacements.

The basic formulæ are used in subsequent chapters on the piezo-electric properties of certain crystals, on alternative formulations of piezo-electricity theory, and on secondary piezo-electric effects. On page 252 of the chapter on alternative formulations of theory, incidentally, the author introduces equations (243) and (243a), which are similar to (1) and (2), and in which again generalized forces and co-ordinates are incorrectly mixed in the Lagrange function.

Prof. Cady's book fills the need for a comprehensive summary of the recent experimental researches; the mathematical portions, however, require revision.

National Bureau of Standards, RICHARD K. COOK

Washington, D.C. Oct. 20.

\section{The Melanin Problem : a Synthesis of 5 : 6-Dihydroxyindole}

We have recently submitted to the Chemical Society a paper describing, inter alia, a new synthesis of 5-hydroxyindole by reduction with iron powder and acetic acid of $2: \beta$-dinitro-5-acetoxystyrene and deacetylation of the resulting 5-acetoxyindole. As a part of a comprehensive investigation of the chem. istry of the natural melanins, we have now successfully extended the method to the synthesis of $5: 6$-diacetoxyindole (compact hemispherical clusters, m.p. $135-136^{\circ}$; found : $\mathrm{C}, 61.5 ; \mathrm{H}, 4.9 ; \mathrm{N}, 6 \cdot 3$ : $\mathrm{C}_{12} \mathrm{H}_{11} \mathrm{O}_{4} \mathrm{~N}$ requires $\mathrm{C}, 6 \mathrm{I} \cdot 8 ; \mathrm{H}, 4.7 ; \mathrm{N}, 6.0$ per cent), and of $5: 6$-dihydroxyindole (colourless needles, m.p. $140^{\circ}$; found : C, $64.7 ; \mathrm{H}, 4.85 ; \mathrm{N}, 9.4$ : $\mathrm{C}_{8} \mathrm{H}_{7} \mathrm{O}_{2} \mathrm{~N}$ requires $\mathrm{C}, 64 \cdot 4 ; \mathrm{H}, 4 \cdot 7 ; \mathrm{N}, 9 \cdot 4$ per cent). The latter compound was postulated by Raper ${ }^{1}$ as an unstable intermediate in the enzyme-catalysed oxidation of tyrosine to melanin, and has been known hitherto only in solution or in the form of its derivatives.

Treatment of the alkaline deacetylation mixture with dimethyl sulphate, without isolation of the hydroxyindole, yielded the dimethyl-ether (m.p. $155^{\circ}$, in agreement with Raper's 5:6-dimethoxyindole, m.p. $154-155^{\circ}$; found : $\mathrm{C}, 67.6$; H, 6.0 ; calculated for $\mathrm{C}_{10} \mathrm{H}_{11} \mathrm{O}_{2} \mathrm{~N} \mathrm{C}, 67 \cdot 8 ; \mathrm{H}, 6 \cdot 2$ per cent).

Crystalline $5: 6$-dihydroxyindole is surprisingly stable, but in slightly alkaline solution very rapid oxidation occurs with formation of melanin-like products. A study of the oxidation of this dihydroxy indole, its alkyl substitution products and related compounds, which have been synthesized, is in active progress.
R. J. S. BEER
K. Clarke
H. G. Khorana
A. Robertson

Department of Organic Chemistry,

University,

Liverpool.

Dec. 16.

${ }^{1}$ Biochem. J., 21, 89 (1927).

\section{The Carotenoids of the Locust Integument}

As part of a research programme into the biochemistry of locust pigmentation, the carotenoids of the integument of Locusta migratoria migratoroides R. and F. and Schistocerca gregaria, Forsk. have been investigated. There is apparently no reference in the literature to the pigment of Locusta, and only two rather tenuous and contradictory reports have appeared concerning that of Schistocerca ${ }^{1,2}$. Lederer ${ }^{1}$ quotes unpublished work with Volkonsky indicating that the rose pigment of young Schistocerca is not a carotenoid but that the yellow pigment of the mature insect is ; Chauvin ${ }^{2}$ reported an unidentified rosecoloured carotenoid in immature, and a mixture of $\alpha$ - and $\beta$-carotene in mature, insects.

The insects used in the present investigation were bred in captivity and fed solely on grass. The pig. ment in the hypodermis of both Locusta and Schisto. cerca is the same and undoubtedly astaxanthin ${ }^{3}$. Its identity has been established by comparing its properties with an authentic specimen of astaxanthin isolated from lobster carapaces. Both compounds gave identical absorption spectra in three solvents, namely, petroleum-ether, b.p. $40-60^{\circ}$, pyridine and carbon disulphide; a mixture of the two pigments could not be separated chromatographically. Further, the locust astaxanthin reacted with potassium butoxide in vacuo to form a purplish-blue enol salt, and was converted into astacene by alkali in the presence of oxygen. The astacene formed was indistinguishable from lobster astacene.

Partition experiments indicate that astaxanthin occurs in the free form and is not esterified. It occurs in both the solitary and gregarious phases, and at all stages of development up to sexual maturity; up to this stage it is the predominant carotenoid present. It must be formed by the insect, for it does not occur in the diet.

At sexual maturity $\beta$-carotene, always present in the fatty tissues of the insects, begins to accumulate in the hypodermis and the astaxanthin to disappear. This observation confirms and explains the work of Chauvin and of Lederer on mature insects. It is, however, difficult to accept unreservedly Lederer's contention that the yellow pigmentation of mature Schistocerca is entirely due to carotenoids; so-called acridioxanthin ${ }^{4}$ undoubtedly plays some part. This disappearance of astaxanthin, with replacement by $\beta$-carotene, at sexual maturity has no obvious explanation at present; but it is another addition to the growing mass of observations which suggests a relationship between carotenoid metabolism and sexual function. It is interesting to note that astaxanthin is also present in the eyes of locusts in both mature and immature insects.

The pigmentation of the gonads and fatty tissues of both species is due almost completely to $\beta$-carotene; there may be a little $\alpha$-carotene present but no traces of xanthophylls could be detected; the amount of $\beta$-carotene which accumulates, especially in older insects, is considerable. Previous workers ${ }^{1}$ have claimed that this pigmentation is due to a mixture of carotenes and xanthophylls but, more recently, Grayson, and Grayson and Tauber ${ }^{6}$ have reported findings on another acridid (Melanoplus bivattus Say.) which are in substantial agreement with ours, although they report the presence of traces of xanthophylls.

The demonstration of astaxanthin in locusts is particularly interesting because, apart from its 